\title{
Novel drug-eluting stents in the treatment of de novo coronary lesions
}

\author{
This article was published in the following Dove Press journal: \\ Vascular Health and Risk Management \\ 24 February 20II \\ Number of times this article has been viewed
}

\author{
Davide Capodanno ${ }^{1,2}$ \\ Fabio Dipasqua' \\ Corrado Tamburino 1,2 \\ 'Department of Cardiology, \\ Ferrarotto Hospital, University \\ of Catania, Catania, Italy; \\ ${ }^{2}$ ETNA Foundation, Catania, Italy
}

Correspondence: Corrado Tamburino

Department of Cardiology,

Ferrarotto Hospital, University

of Catania, Via Citelli 6,

95124 Catania, Italy

Tel +39095743620 I

Fax +39095362429

Email tambucor@unict.it

\begin{abstract}
Due to safety concerns in recent years, much effort has been devoted to improving the outcomes associated with drug-eluting stents (DESs). This review summarizes the current status of methodological and technical achievements reported in second-generation DES. Novel stents are described based on the component (the platform, the polymer, and the drug) that has undergone the most significant changes compared to earlier generation DES. An overview of the currently available evidence on the use of novel coronary devices in patients undergoing coronary revascularization is also reviewed.
\end{abstract}

Keywords: coronary artery disease, stent, platform, polymer, drug, percutaneous coronary intervention, late lumen loss, follow-up, outcomes

\section{Introduction}

The introduction of first-generation drug-eluting stents (DESs) in the setting of percutaneous coronary intervention (PCI) has led to a significant decrease in the need for repeat revascularization, a common limitation associated with the use of bare-metal stents (BMS). In-stent restenosis, the result of a maladaptive neointimal tissue proliferation, is dramatically reduced by the long-lasting inhibitory effect exerted by the local elution of antiproliferative agents. ${ }^{1-3}$

First-generation DES commonly consist of three elements: an antiproliferative drug, a durable polymer that serves for drug loading and modification of release kinetics, and the stent platform (Figure 1). The first generation of DES employs a cobaltchromium alloy, a durable polymer, and elutes sirolimus (Cypher; Cordis, Warren, NJ) or paclitaxel (TAXUSTM; Boston Scientific, Natick, MA). Sirolimus- and paclitaxeleluting stents seem to provide similar rates of revascularization, although several studies report a more profound inhibition of neointimal hyperplasia by sirolimus. ${ }^{4-6}$ While other first-generation DES have been produced, ${ }^{7}$ the second-generation DES now include the zotarolimus- (Endeavor; Medtronic, Minneapolis, MN) and the everolimus- (Xience V; Abbott Vascular, Redwood City, CA) eluting stents. ${ }^{8,9}$

Despite the higher efficacy compared to BMS, concerns remain regarding the long-term safety of DES, including localized hypersensitivity and late stent thrombosis. ${ }^{10-12}$ Although the exact mechanisms of these pathological reactions have not yet been fully elucidated, they seem to be most likely associated with the presence of durable polymers, representing a trigger for inflammation and subsequent impaired re-endothelialization. ${ }^{13}$ In previous years, several efforts have been devoted by researchers to address these limitations of DES. In particular, attention has been focused on 


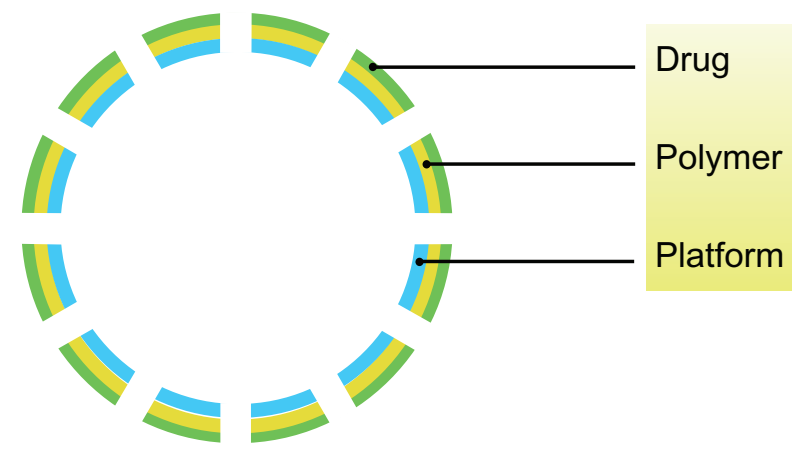

Figure I Schematic representation of the structure of a conventional DES.

possible advancements of platform, carrier, and pharmacological technologies, and many innovations have been provided aiming at improving biocompatibility and long-term outcomes of patients undergoing PCI.

This review summarizes the current status of methodological and technical achievements reported in secondgeneration DES, giving an account of the most recent clinical data and the latest improvements in treatment of de novo coronary lesions. For the purpose of the following discussion, novel stents will be described based on the component (the platform, the polymer, and the drug) that has undergone the most significant changes compared to earlier generation DES (Figure 2). We searched Medline to identify studies which assessed second-generation DES, using search terms such as 'novel stents', 'second-generation drug eluting stent', 'stent polymer', and 'biodegradable stents'. In addition, we identified relevant abstracts and presentations at the annual meetings of the American Heart Association, the American College of Cardiology, the European Society of Cardiology, the European Association of Percutaneous Coronary Intervention, Transcatheter Cardiovascular Therapeutics, and Transcatheter Cardiovascular Therapeutics Asia Pacific from July to September 2010. Expert slide presentations were consulted online from tctmd.com to complete data from abstracts. Internet-based sources of information on the results for clinical trials in cardiology (see http:// www. theheart.org and http://www.tctmd.com) were also searched.

\section{Innovations in stent platforms}

Recent innovations in stent platforms include changes of the metallic alloy (ie, shifting from cobalt-chromium or stainless steel to platinum-chromium platforms) or development of dedicated stent platforms for the treatment of specific subsets of lesions (ie, bifurcations and small-vessel lesions).

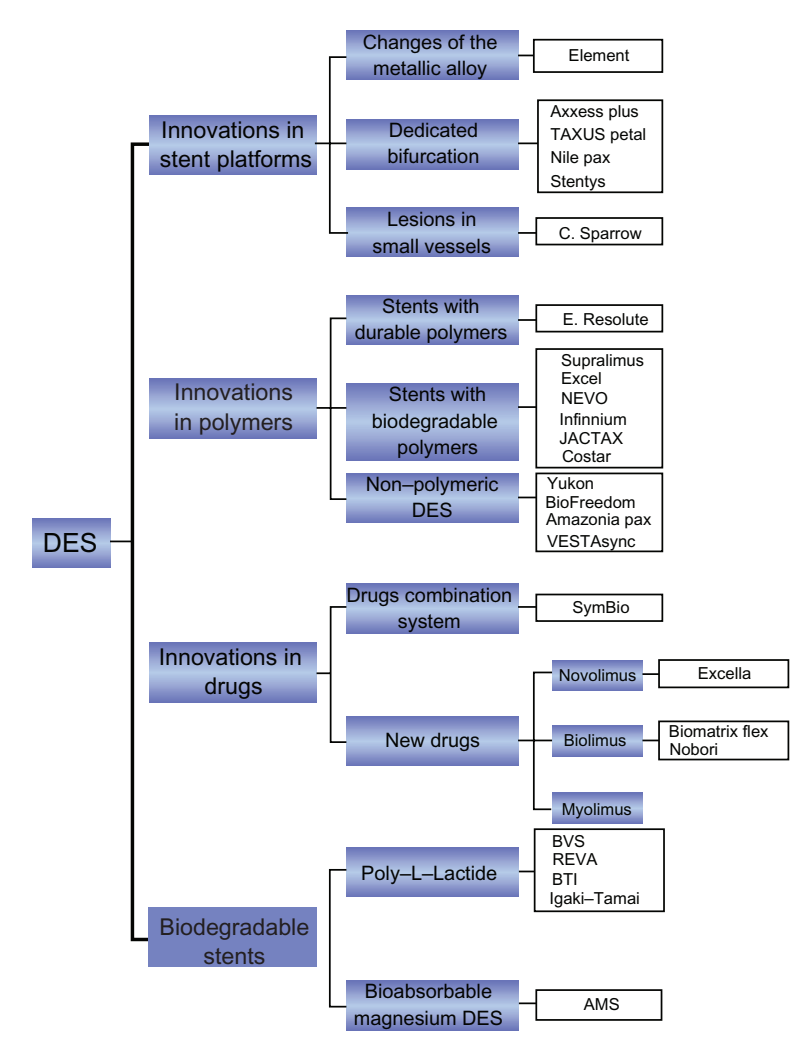

Figure 2 Diagram of topics and stents described in this review.

Abbreviations: AMS, absorbable-metal stent; BVS, bioresorbable vascular scaffold; DES, drug-eluting stents.

\section{Changes of the metallic alloy}

\section{Element ${ }^{\mathrm{TM}}$ Stent Platform}

The Element Stent Platform (Boston Scientific) is made up of a platinum-chromium alloy. The platinum-chromium platform has a new stent architecture with a thin strut thickness $(81 \mu \mathrm{m})$, which features high radiopacity, high radial strength, and conformability. The Element Stent Series includes an everolimus-eluting (PROMUS Element ${ }^{\mathrm{TM}}$; Boston Scientific) and a paclitaxel-eluting stent (TAXUS ${ }^{\text {TM }}$ Element; Boston Scientific). Both stents have received the Conformité Européenne (CE) Mark.

The safety and effectiveness of the PROMUS Element stent for the treatment of de novo atherosclerotic coronary lesions are the object of the ongoing prospective, randomized, multicenter PLATINUM (Clinical Trial to Assess the PROMUS Element Stent System for Treatment of De Novo Coronary Artery Lesions) trial (Clinicaltrials.gov identifier NCT00823212). In the prospective, randomized PERSEUS (Prospective Evaluation in a Randomized Trial of the Safety and Efficacy of the Use of the TAXUS Element Paclitaxel-Eluting Coronary Stent System) Workhorse trial (NCT00484315), the TAXUS Element has proven to be 
noninferior to the first-generation TAXUS Express with regard to the incidence of 12-month target lesion failure (TLF) $(5.6 \%$ vs $6.1 \%$ for TAXUS Element and TAXUS Express, respectively, $P=0.78$ ) for the treatment of de novo atherosclerotic lesions of up to $28 \mathrm{~mm}$ in length in native coronary arteries of 2.75-4.0 $\mathrm{mm}$ diameter. In addition, there were no differences in terms of in-stent late loss between the two stents $(0.34 \pm 0.55$ vs $0.26 \pm 0.52 \mathrm{~mm}, P=0.33)$ at 9 -month follow-up. ${ }^{14}$ Conversely, the TAXUS PERSEUS Small Vessel trial (NCT00489541) is a prospective, multicenter, single-arm superiority trial, currently ongoing, which aims to assess the safety and efficacy of the TAXUS Element stent for the treatment of de novo atherosclerotic lesions $\leq 20 \mathrm{~mm}$ in length in native coronary arteries of $\geq 2.25$ to $<2.75 \mathrm{~mm}$ diameter.

\section{Dedicated bifurcation stents}

The dedicated stents have been developed with the goal of addressing some of the most common issues associated with PCI of a bifurcation lesion, including difficulties in maintaining side-branch access throughout the procedure, main vessel stent struts jailing the side-branch ostium, distortion of main vessel stent after side-branch dilatation, and failure to cover and scaffold the side-branch ostium. ${ }^{15}$ First-generation bifurcation-dedicated BMS include the Multi-Link Frontier ${ }^{\mathrm{TM}}$ (Guidant Corp, Santa Clara, CA), ${ }^{16}$ the SLK-View ${ }^{\text {TM }}$ (Advanced Stent Technologies, Pleasanton, CA), ${ }^{17}$ the Petal ${ }^{\mathrm{TM}}$ (Advanced Stent Technologies), ${ }^{18}$ the Sideguard ${ }^{\mathrm{TM}}$ (Cappella Inc, Galway, Ireland), ${ }^{19,20}$ the Twin-Rail ${ }^{\mathrm{TM}}$ (Invatec Srl, Roncadelle, Italy), ${ }^{21}$ the Nile Croco ${ }^{\mathrm{TM}}$ (Minvasys, Genevilliers, France), ${ }^{22}$ the Tryton $^{\mathrm{TM}}$ (Tryton Medical Inc, Durham, NC), ${ }^{23}$ the Sidekick ${ }^{\mathrm{TM}}$ (Y-med Inc, San Diego, CA), ${ }^{24}$ and the Antares SAS ${ }^{\text {TM }}$ (TriReme Medical Inc, Pleasanton, CA). ${ }^{25}$ These stents lack a drug-eluting coating and are associated with a high rate of restenosis ranging between $28 \%$ and $54 \% .{ }^{26} \mathrm{~A}$ new generation of bifurcation-dedicated DES is currently under clinical investigation and will be discussed in the following paragraphs.

\section{Axxess Plus ${ }^{\mathrm{TM}}$}

The Axxess (Devax Inc, Irvine, CA) stent is a self-expanding nickel-titanium alloy stent featuring a conical configuration designed to conform with the bifurcation anatomy, which provides easy access to the distal branches for easy placement of subsequent stents (Figure 3). The stent is coated with a resorbable polymer which elutes Biolimus A9. The Axxess Plus registry reported low in-stent late loss $(0.09 \pm 0.56 \mathrm{~mm})$ and restenosis $(4.8 \%)$ with the Axxess stent

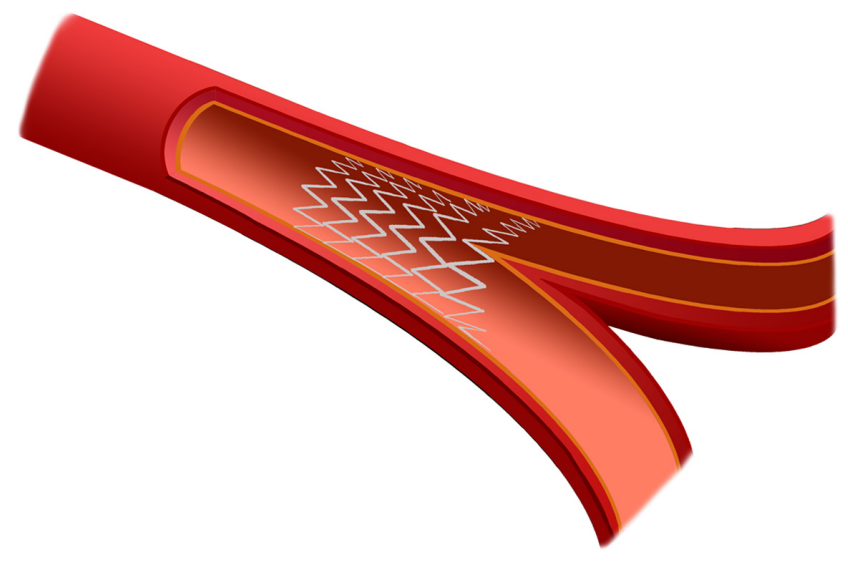

Figure 3 Representation of the self-expanding nickel-titanium Axxess stent in its definitive placement after deployment.

at 6 months follow-up. ${ }^{27}$ The DIVERGE (Drug-Eluting Stent Intervention for Treating Side Branches Effectively) study $(n=302)$ showed encouragingly low major adverse cardiac events (MACEs) (7.7\%) and target lesion revascularization (TLR) rates $(4.3 \%)$ at 9 months follow-up. ${ }^{28}$ The randomized COBRA (COmplex BifuRcation Lesions: A Comparison Between the AXXESS Device and Culotte Stenting: An Optical Coherence Tomography) study (NCT00895791) will enroll 40 patients and assess vessel healing at 9 months by optical coherence tomography (OCT) in bifurcation lesions treated using the Axxess stent or the culotte technique. This stent has received the CE Mark in July 2010.

\section{TAXUS Petal ${ }^{\mathrm{TM}}$ stent}

The TAXUS Petal (Boston Scientific) dedicated stent is the improved version of the AST Petal stent, acquired by Boston Scientific in 2004. Its platinum-chromium platform is stronger and more radiopaque than a stainless steel platform with four radiopaque markers for good visualization on angiography and includes a main branch section with a side-branch opening to provide mechanical scaffolding and drug delivery to the side-branch ostium. The TAXUS Petal stent is coated with the same poly(styrene-b-isobutylene-b-styrene) polymer as the TAXUS Express and the TAXUS Libertè stents and releases paclitaxel in the same manner. The first-in-man study of the TAXUS Petal stent reported a composite rate of all death, myocardial infarction (MI), or target vessel revascularization (TVR) of $3.7 \%$ and $14.8 \%$ at 30-day and 12 -month follow-up, respectively, 6-month in-segment late loss of $0.47 \pm 0.45$ and $0.41 \pm 0.57 \mathrm{~mm}$ for the proximal and distal main branch, respectively, and $0.18 \pm 0.39 \mathrm{~mm}$ for the side branch. $^{29}$ 


\section{Nile $\mathrm{Pax}^{\mathrm{TM}}$}

The Nile Pax (Minvasys) dedicated stent is a chromiumcobalt stent, with a 73- $\mu \mathrm{m}$ strut thickness and a modular design, developed using the Pax technology, previously utilized in the Amazonia Pax stent. Similar to this latter stent, the Nile Pax is characterized by a polymer-free paclitaxel abluminal coating to avoid long-term lack of endothelization and to deliver the drug exclusively onto the arterial wall. Paclitaxel is applied using a microdrop spray crystallization process. The stent has a dedicated bifurcation delivery system made of specific balloon catheters. ${ }^{30}$ The safety and efficacy of this novel stent is currently evaluated in the prospective, nonrandomized, single-arm multicenter BIPAX (dedicated bifurcation with the PAX technology) trial on 102 patients. Preliminary results have demonstrated good results for the treatment of de novo bifurcation lesions including high acute success $(99 \%)$, neither cardiac death nor stent thrombosis at 30 days clinical follow-up and absence of thrombotic events after hospital discharge. ${ }^{31}$

\section{STENTYS TM}

The STENTYS (Stentys S.A.S., Paris, France) dedicated stent is a provisional, self-expanding nitinol stent developed both as a DES and as a BMS. The main peculiarity of this stent is the possibility of creating a side-branch access anywhere in the stent after implantation in the main vessel. The side-branch opening is created by inflating the angioplasty balloon into the mesh, thus, disconnecting the interconnections. The drug-eluting form elutes paclitaxel (dose: $0.8 \mu \mathrm{g} / \mathrm{mm}^{2}$ ) which is loaded in a blend of a durable polymer of polysulfone and polyvinyl-pyrrolidone. In the first-in-man trial of 40 patients, the stent showed a $95.5 \%$ procedural success rate, which is defined as technical and angiographic success in the absence of any MACE at hospital discharge. Disconnection of the strut to create the side-branch opening was successfully achieved in $95 \%$ of patients. After stent implantation in the main branch, stenting the side branch was necessary in onethird of the cases. ${ }^{32}$ In the prospective, nonrandomized, multicenter APPOSITION I study $(\mathrm{n}=25)$, the in-stent late loss was $0.71 \pm 0.70 \mathrm{~mm}$ and the rate of angiographic restenosis $(>50 \%)$ was $25 \%$ at 6 months; no cases of death, stent thrombosis, or MI were noted at the same follow-up. ${ }^{33}$ In the randomized, multicenter APPOSITION II study (NCT01008085), 80 patients with ST-elevation myocardial infarction (STEMI) were randomized to the STENTYS stent versus a conventional balloon-expandable stent and followed up with OCT for 3 days. Preliminary data reported a significant reduction in stent strut malapposition with the STENTYS stent $(0.51 \%$ vs $5.33 \%, P<0.001) .{ }^{34}$ This stent has received the CE Mark in May 2010.

\section{Lesions in small vessels}

A small vessel diameter is still an independent predictor of angiographic and clinical restenosis. DES have been employed for the treatment of lesions located in the small vessels, but their impact on clinical and angiographic outcomes is not yet well established. It can be expected that DES implantation could bring a reduction in restenosis and the need for repeat revascularization, as shown in several studies, but large, randomized studies are necessary to elucidate the safety and efficacy of both traditional and next-generation DES in this scenario..$^{35,36}$

\section{Cardiomind Sparrow ${ }^{\mathrm{TM}}$}

The Cardiomind Sparrow (Biosensors, Morges, Switzerland) stent is a self-expanding nitinol stent loaded into a $0.014^{\prime \prime}$ guidewire platform, which is developed to treat lesions in small vessels. It has a closed cell design and an ultrathin strut $\left(0.0024^{\prime \prime}\right)$. The stent is deployed through a proprietary mechanism, which enables the electrolysis of mechanical latches at each end of the device. This process is initiated and controlled by electrical energy delivered from a handheld battery. ${ }^{37}$

Two versions of the Cardiomind Sparrow stent have been developed. The first version was a BMS assessed in the prospective, multicenter, feasibility CARE I study that enrolled 22 patients and reported a rate of MACE of $9.5 \%$ at 24-month follow-up and an in-stent late lumen loss of $0.73 \pm 0.57 \mathrm{~mm}$ at 6 -month follow-up. ${ }^{38}$ The second version is a DES with a strut thickness of $67 \mu \mathrm{m}$ (compared to $140 \mu \mathrm{m}$ of Cypher stent and $132 \mu \mathrm{m}$ of TAXUS stent) in which the antiproliferative agent sirolimus is combined in the SynBiosys ${ }^{\mathrm{TM}}$ polylactic acid (PLA) biodegradable copolymer matrix. The dose of the drug is $\sim 6 \mu \mathrm{g} / \mathrm{mm}$. This second-generation stent was compared to the BMS version tested in the CARE I study and traditional BMS in the prospective, multicenter, multinational three-arm randomized CARE-II study. The trial showed an in-stent late lumen loss of $0.29 \pm 0.45 \mathrm{~mm}$ in the sirolimus-eluting stent arm versus $0.86 \pm 0.54$ of bare metal Cardiomind and $0.99 \pm 0.45 \mathrm{~mm}$ of BMS at 8 -month follow-up; the rates of binary restenosis were $6.7 \%, 45.2 \%$, and $44.0 \%$, respectively, and the rates of cumulative MACE were $6.25 \%, 8.6 \%$, and $16.7 \%$ at the same follow-up..$^{39,40}$ 


\section{Conclusions}

The innovations in stent platform discussed in this section anticipate promising results, in particular for the treatment of challenging lesions, such as long lesions, bifurcations lesions, and those located in small vessels, but larger studies with adequate follow-up are needed to evaluate the safety of novel metal alloys and modified stent designs.

\section{Innovations in polymers Stents with durable polymers \\ Endeavour Resolute ${ }^{\mathrm{TM}}$}

The Endeavour Resolute (Medtronic CardioVascular Inc, Santa Rosa, CA) is a next-generation zotarolimus-eluting stent developed by Medtronic to improve the clinical outcomes associated with the first-generation Endeavor stent. It is comprised of a Driver cobalt-chromium stent platform, similar to the Endeavor stent, the antiproliferative agent zotarolimus, and, instead of the Endeavor stent's phosphorylcholine polymer, a new biocompatible polymer called BioLinx ${ }^{\mathrm{TM}}{ }^{41}$ This polymer is a blend of three different polymers, a hydrophobic $\mathrm{C} 10$ polymer, a hydrophilic C19 polymer, and a hydrophilic polyvinyl-pyrrolidinone, designed to provide a robust coating and to enhance polymer biocompatibility, reducing the risk of delayed healing and late stent thrombosis. The polymer also extends the duration of drug exposure in the vessel, such that $\sim 50 \%$ of the zotarolimus is released within the first week, with the remaining drug released beyond 31 days. ${ }^{42}$

The stent's clinical effectiveness and safety have been evaluated in 139 patients enrolled in the prospective, multicenter, nonrandomized, single-arm, controlled first-in-man RESOLUTE trial, which showed a late lumen loss of $0.22 \pm 0.27 \mathrm{~mm}$ and an in-stent binary restenosis of $1.0 \%$ at 9 months angiographic follow-up. ${ }^{41}$ The cumulative rates of MACE, TLR, and target vessel failure (TVF) reported at 2-year follow-up were $10.1 \%, 1.4 \%$, and $7.9 \%$, respectively. ${ }^{43}$

Recently, the Endeavour Resolute stent has been compared to the Xience ${ }^{\mathrm{TM}} \mathrm{V}$ everolimus-eluting stent in the prospective, multicenter, randomized, two-arm, international, noninferiority RESOLUTE-III all-comers trial (NCT00617084), in which 2300 patients were enrolled. The results of this study showed the Resolute to be noninferior to Xience $\mathrm{V}$ for the primary endpoint of composite TLF (cardiac death, target vessel MI, or clinically driven TLR) at 12 months follow-up (Resolute $8.2 \%$ vs Xience V 8.3\%, $\left.P_{\text {noninferiority }}<0.001\right){ }^{44}$

The Endeavour Resolute stent has received the CE Mark in 2007.

\section{Excella $^{\mathrm{TM}}$ stent}

This stent is described in the Innovations in drugs - New drugs section.

\section{Stents with biodegradable polymers}

\section{Sirolimus-based}

Supralimus ${ }^{\mathrm{TM}}$

The Supralimus stent (Matrix; Sahajanand Medical Technologies, Surat, Gujarat, India) is a stainless steel stent with a twolayer biodegradable polymer coating. The base layer is a mix of poly-L-lactic acid (PLLA), poly-lactide-co-glycolide, and polyvinyl-pyrrolidone, which releases $50 \%$ of sirolimus within the first week and the remaining $50 \%$ in the next 41 days. The surface polyvinyl-pyrrolidone layer has a protective function and degrades completely within $2 \mathrm{~h}$ after implantation.

In the prospective, nonrandomized, first-in-man SERIES I study, 100 patients were treated with the Supralimus stent. Data showed a 6\% rate of MACE at 9 months follow-up and an event-free survival rate of $93 \%$ at 30 months. The rates of 6-month in-stent and in-segment restenosis in a prespecified subgroup of 60 patients were $0 \%$ and $1.7 \%$, respectively; the in-stent and in-segment late loss were $0.09 \pm 0.28$ and $0.02 \pm$ $0.37 \mathrm{~mm}$, respectively, at the same angiographic follow-up. ${ }^{45}$

The safety and efficacy of the Supralimus stent in the treatment of unselected patients with acute coronary syndrome undergoing PCI have been evaluated in the prospective, multicenter E-SERIES registry which showed acceptable rates of MACE, TLR, and stent definite and probable thrombosis of $10.0 \%, 2.7 \%$, and $0.6 \%$, respectively, at 12 months follow-up. ${ }^{46}$

Further data will be produced by the prospective, multicenter, randomized, noninferiority SERIES III trial (NCT00917163), which is currently ongoing. This study includes a head-to-head comparison with the Xience V stent for the primary endpoint of in-stent luminal late loss at 9 months after stent implantation.

\section{Excel $^{\mathrm{TM}}$}

The Excel stent (JW Medical Co Ltd, Shandong Province, Weihai, China) is composed of the S-Stent's (Biosensor International) stainless steel laser-cut platform, which confers a high flexibility, a very thin coating $(10-15 \mu \mathrm{m})$ of sirolimus, and a PLA biodegradable polymer, which can be expected to have a complete degradation within 6-9 months. The Excel stent has been investigated in the CREATE (Multi-Center Registry Trial of EXCEL Biodegradable Polymer DrugEluting Stent, NCT00331578) registry in 2077 patients. 
The predefined primary endpoint was the incidence of MACE (cardiac death, nonfatal MI, and TLR) at 12 months follow-up after stent implantation. The trial reported MACE rates of $2.7 \%$ and $3.1 \%$ at 12 - and 18-month follow-up, respectively, and an angiographic in-stent late lumen loss of $0.21 \pm 0.39 \mathrm{~mm} .{ }^{47}$ In this study, $80.5 \%$ of patients discontinued clopidogrel treatment within 6 months, given the use of a biodegradable polymer. The rate of stent thrombosis proved to be $0.87 \%$ at 18 months of follow-up.

\section{NEVOTM}

The NEVO stent (Cordis) is made up of a cobalt-chromium alloy platform, with open cell design to improve vessel conformability. It is the first DES applying the Cordis RES Technology ${ }^{\mathrm{TM}}$, which consists of hundreds of reservoirs embedded in the struts, each acting as a depot loaded with a drug-polymer mix. The active ingredient in the drugpolymer composition is sirolimus, with similar drug dose and release kinetics as Cypher. The polymer loaded into reservoirs is a poly-lactic acid-co-glycolic acid (PLGA). Polymer's degradation time can be controlled by altering the lactide/glycolide ratio, and specifically for NEVO stent, PLGA completes bioabsorption in a very short duration of 90 days. This technology offers several advantages, first a higher drug/polymer ratio and thus both higher drug dose and lower polymer mass than conventional DES. Moreover, reservoirs coat a small percentage of stent surface, which is therefore for the most part bare metal, in contrast to other DESs that are totally polymer coated. This feature conceivably increases stent vessel biocompatibility. ${ }^{48}$

In the randomized, multicenter, single-blind NEVO RES-I (Comparison of the Conor Sirolimus-eluting Coronary Stent to the TAXUS Liberté Paclitaxel-eluting Coronary Stent in the Treatment of Coronary Artery Lesions, NCT00606333) trial, the NEVO stent was compared to the TAXUS Liberté paclitaxel-eluting coronary stent in 394 patients. NEVO was associated with significantly lower in-stent late lumen loss ( 0.13 vs $0.36 \mathrm{~mm}, P<0.001)$ at 6 -month quantitative coronary angiography (QCA) follow-up. ${ }^{49}$ In addition, NEVO showed lower rates of death $(0.5 \%$ vs $2.2 \%)$, MI $(2.0 \%$ vs $3.2 \%$ ), MACE (6.1\% vs $10.8 \%)$, and TLR (3.6\% vs $5.9 \%)$ than TAXUS at 12 months follow-up. No cases of stent thrombosis occurred at the same follow-up in the NEVO group in contrast with two late thromboses (one possible and one probable) in the TAXUS group..$^{50}$ Further studies have been designed to investigate the NEVO stent, such as the ongoing prospective, multicenter NEVO RES-II study (NCT00714883). The NEVO II trial (NCT01202058) will be a randomized, noninferiority trial comparing the NEVO stent to the Xience everolimus-eluting coronary stent with the aim of assessing clinical outcomes during 5 years of follow-up. The prospective CYNERGY (Cynergy: the CYPHER-NEVO Registry) study (NCT01106378) is recruiting participants to assess the noninferiority of NEVO, once commercially available, to CYPHER in patients with acute STEMI, diabetes mellitus, or multivessel disease.

\section{Biolimus-based}

The BioMatrix Flex stent and the Nobori stent, both coated with a biodegradable polymer, are described in the Innovations in drug - New drugs section.

\section{Paclitaxel-based \\ Infinnium ${ }^{\mathrm{TM}}$}

The biodegradable polymers, which coat the stainless steel balloon-expandable platform of the Infinnium stent (Matrix; Sahajanand Medical Technologies) are poly-L-lactide, polyDL-lactide-co-glycolide, poly-L-lactide-co-caprolactone, and polyvinyl-pyrrolidone. These polymers are stratified in composition with the antiproliferative agent paclitaxel, each layer with a different drug release kinetics. Infinnium stent's safety and efficacy have been assessed in 103 patients enrolled in the multicenter, prospective, nonrandomized SIMPLE II study, which aimed at investigating the incidence of MACE (primary endpoint) at 30 days and in-stent binary restenosis by QCA at 6 months follow-up. Results showed rates of MACE at 30 days, 6 months, and 9 months to be $2.9 \%, 4.9 \%$, and 9.7\%, respectively. Data from QCA indicated in-stent and in-segment binary restenosis rates of $7.3 \%$ and $8.3 \%$ associated with in-stent and in-segment late loss of $0.38 \pm 0.49$ and $0.18 \pm 0.46 \mathrm{~mm}$, respectively. ${ }^{51}$

The Infinnium stent has been compared with the abovementioned Supralimus stent and a BMS control in the randomized, multicenter PAINT trial (NCT00752362), which reported a significant reduction in late loss and TVR at 9 months follow-up for DES (both Infinnium 0.54-0.44 mm and Supralimus $0.32-0.43 \mathrm{~mm}$ ) compared with BMS $(0.90-0.45 \mathrm{~mm}) .^{52}$ This stent has received the CE Mark.

\section{JACTAXTM}

The JACTAX ${ }^{\mathrm{TM}}$ (Boston Scientific) Liberté is made up of a premounted stainless steel platform coated with a polymerdrug blend of a low molecular weight biodegradable polylactide polymer and paclitaxel. This process, known as Juxtaposed Abluminal Coating technology, applies minimal amount of polymer-drug composition in discrete areas 
(2750 microdots/16 $\mathrm{mm}$ stent) exclusively located onto the abluminal surface, such that the other three sides of the stent remain BMS surface. Polymer thickness is $\leq 1 \mu \mathrm{m}$, approximately 15 times thinner than that of the TAXUS Liberté stent polymer. The drug paclitaxel is fully released in 60 days, while the polymer degrades within 4 months.

The prospective, single-center, randomized OCTDESI (Optical Coherence Tomography Drug Eluting Stent Investigation) trial (NCT00776204) was designed to evaluate the long-term proportion of strut coverage and the vessel wall response with the JACTAX stent at 6 months, with either low drug dose (LD) or high drug dose (HD), compared to the TAXUS Libertè stent. Data showed that the primary endpoint of the percentage of uncovered stent struts per patient at 6 months follow-up measured by OCT was similar for the three devices $(5.3 \% \pm 14.7 \%$ for TAXUS Liberté, $7.0 \% \pm 12.2 \%$ for JACTAX HD, and $4.6 \% \pm 7.3 \%$ for JACTAX LD; $P=0.81){ }^{53,54}$ There were no deaths, Q wave MIs, or stent thromboses at 12-month clinical follow-up.

An evaluation of safety and clinical performance of the JACTAX HD stent have been performed in a prospective, multicenter, nonrandomized first-in-man study (NCT00754728), which recruited 103 patients who had underwent PCI with the aforementioned stent compared to an historical control group of patients treated with the TAXUS Liberté stent from the ATLAS trial. ${ }^{55}$ Results in patients treated with JACTAX HD stent showed that the primary endpoint of MACE (cardiac death, MI, and ischemia-related TVR) occurred at 9 months in $7.8 \%$ of patients, a value significantly below the $17 \%$ noninferiority limit, thus meeting the prespecified criteria for noninferiority to the TAXUS Liberté stent. Moreover, there was no death, Q wave MI, or stent thrombosis during follow-up. Results of QCA demonstrated an in-stent late loss of $0.33 \pm 0.45 \mathrm{~mm}$ and an in-stent binary restenosis of $5.2 \%$, which are comparable values to those observed in similarmatched patients from the TAXUS ATLAS trial. Mean net volume obstruction by intravascular ultrasound (IVUS) was $11.4 \% \pm 11.2 \%{ }^{56}$ The JACTAX LD stent has been assessed in the prospective, multicenter, randomized JACTAX LD Drug Eluting Stent Trial (NCT00754975) and completed in August 2010. This trial randomized 130 patients from the JACTAX LD stent or the TAXUS Libertè. The study results are awaited.

\section{CoStar ${ }^{\mathrm{TM}}$}

The CoStar stent (Conor MedSystems, Menlo Park, CA) is a cobalt-chromium stent that elutes paclitaxel without the use of a surface polymer using holes located on the surface of the stent, each one acting as a reservoir for a drug-polymer blend. The polymer loaded into the reservoirs is a bioresorbable PLGA polymer, which degrades mediating drug delivery such that at the end of biodegradation process, only the baremetal platform remains. The CoStar stent was first evaluated in several study (PISCES and COSTAR I ed EuroStar) and showed satisfactory results. ${ }^{57-59}$ However, in the multicenter, single-blind, two-arm, randomized, controlled, noninferiority trial COSTAR II study (NCT00165035) ( $\mathrm{n}=1700)$, the CoStar stent was not demonstrated to be noninferior in clinical and angiographic performance compared with the paclitaxeleluting TAXUS stent: the MACE rate was $11.0 \%$ for Costar and $6.9 \%$ for TAXUS $(P<0.005)$ at 8 -month follow-up, and the in-segment late loss was $0.49 \mathrm{~mm}$ for CoStar and $0.18 \mathrm{~mm}$ for Taxus $(P<0.0001) .{ }^{60}$ The CoStar stent has received the CE Mark.

\section{Nonpolymeric stent YUKON ${ }^{\circledR}$}

A microporous stainless steel platform forms the basis of the completely polymer-free YUKON stent (Translumina, Hechingen, Germany), which has been combined with rapamycin using a technology denominated ISAR (Individualised Drug-Eluting Stent System to Abrogate Restenosis). This technology consists of a two-component system, a mobile stent-coating device for the spraying process of the drug and a disposable stent cartridge holding the premounted stainless steel microporous stent. The ISAR process allows to coat the platform with various drugs directly on-site customizing the drug dose. During the coating process, as soon as the two components are correctly located, the drug is sprayed on the stent surface, and it is subsequently dried by removing the ethanol with pressured air. The entire process takes $\sim 8 \mathrm{~min} .{ }^{61}$ According to previous studies, ISAR stents are safe and effective with a $2 \%$ rapamycin-coating solution. ${ }^{62}$ The microporous surface has the function of drug reservoir and retards drug release, consequently the polymer serves no function.

In the randomized ISAR-TEST, in which a total of 450 patients were enrolled, the YUKON stent has been compared to the polymer-based, paclitaxel-eluting TAXUS stent for the treatment of de novo coronary lesions, with the aim of assessing the noninferiority of the rapamycin-eluting stent. The results of the study demonstrated that the YUKON stent is noninferior to the TAXUS stent with regards to the incidence of angiographic and clinical restenosis. ${ }^{63}$ In the prospective, randomized ISAR-TEST-3 (Rapamycin-Eluting Stents With Different Polymer Coating to Reduce Restenosis), the Yukon DES was compared to a rapamycin-eluting stent 
with biodegradable polymer and to a rapamycin-eluting stent with permanent polymer (Cypher) in 605 patients. The study was completed in 2007 and reported a 6- to 8-month in-stent late loss of $0.47 \mathrm{~mm}$ for the YUKON stent compared with $0.17 \mathrm{~mm}$ for the rapamycin-eluting stent with biodegradable polymer and $0.23 \mathrm{~mm}$ for Cypher, showing low efficacy for the polymer-free YUKON stent. ${ }^{64}$

The safety of the YUKON stent has also been evaluated in a real-world registry $(n=410)$, in which a group of patients treated with YUKON stent was compared to a group of those who had undergone PCI with TAXUS stent. This study showed no statistically significant differences in terms of MACE at 6 months follow-up between the two groups of patients; specifically, one MI occurred in the TAXUS stent group and no case in the YUKON stent group $(0.2 \%$ vs $0 \%$, respectively), and 15 TLR $(7.3 \%)$ were performed in the YUKON stent group versus 7 in the TAXUS stent group $(3.4 \%) .{ }^{65}$ A prospective, observational study weighed the difference in in-stent late lumen loss between 6-8 months and 2 years in patients treated with permanent-polymer DES Cypher or TAXUS or with polymer-free rapamycineluting stents. Angiographic data obtained after 2-year follow-up indicate that the absence of permanent polymer from DES has a protective function against delayed in-stent late lumen loss (YUKON stent $0.01 \pm 0.42 \mathrm{~mm}$, Cypher stent $0.17 \pm 0.50 \mathrm{~mm}$, and TAXUS stent $0.13 \pm 0.50 \mathrm{~mm}$ $P<0.001) .{ }^{66}$ This stent has received the CE Mark and is available for sale in Europe.

\section{BioFreedom $^{\mathrm{TM}}$}

The BioFreedom (Biosensors) stent is a stainless steel polymer-free stent, currently under development and releasing Biolimus A9тм, a rapamycin derivate with immunosuppressive and antiproliferative properties which has already been used on the BioMatrix, Nobori, Xtent, and DEVAX stents. In the first cohort of the prospective, multicenter, randomized, single-blinded BioFreedom FIM Clinical Trial (NCT01172119), the stent was compared to the TAXUS Libertè stent in two-drug dosage versions, namely a standarddose version (SD, $15.6 \mu \mathrm{g} / \mathrm{mm}$ of stent length) and a LD version $(7.8 \mu \mathrm{g} / \mathrm{mm}$ of stent length). The 4-month follow-up results reported in the first cohort $(\mathrm{n}=74)$ showed a significant reduction $(P<0.0001)$ of in-stent late loss in both the BioFreedom SD and LD groups (0.08 and $0.12 \mathrm{~mm}$, respectively), compared to the TAXUS Libertè group $(0.37 \mathrm{~mm})$. In addition, no cases of stent thrombosis were noticed in the study during 4 months. The 12-month angiographic follow-up of the second cohort $(n=107)$ demonstrated the noninferiority of the BioFreedom SD compared to TAXUS stent with regard to in-stent late loss $(0.17$ vs $0.35 \mathrm{~mm}$, respectively; $P=0.001$ ) and a trend toward superiority $(P=0.11)$. The rates of MACE at the same follow-up were $6.1 \%$ for BioFreedom SD, $11.6 \%$ for BioFreedom LD, and $5.5 \%$ for TAXUS stent in all patients (first and second cohorts), with no case of stent thrombosis. ${ }^{67}$ In a recent study, the BioFreedom stent showed equivalent early and superior late reduction of neointimal proliferation compared with the polymer-coated sirolimus-eluting Cypher stent in a porcine model. ${ }^{68}$

\section{Amazonia $\mathrm{Pax}^{\circledR}$}

The Amazonia Pax stent (Minvasys) is made up of a polymerfree chromium-cobalt alloy platform, with open cell design, eluting the antiproliferative agent paclitaxel. The drug layer (thickness: $5 \mu \mathrm{m}$ ) is applied using a microdrop spray crystallization process, exclusively onto the abluminal surface, and is loaded with a paclitaxel dose of $2.5 \mu \mathrm{g} / \mathrm{mm}^{2}$. The stent is designed to release $\sim 98 \%$ of the drug in 30 days, returning to regular chromium-cobalt after 45 days. Strut and coating thicknesses are 73 and $5 \mu \mathrm{m}$, respectively, ensuring a total stent thickness of $78 \mu \mathrm{m}$, less than that found on other stents (Cypher stent: $152.6 \mu \mathrm{m}$ and TAXUS stent: $148 \mu \mathrm{m})$. Clinical evaluation of the Amazonia Pax stent is currently ongoing in the prospective, randomized, multicenter-active controlled, single-blinded PAX A trial and in the prospective, nonrandomized PAX B trial. The 4 months follow-up results of the PAX A trial, in which the Amazonia Pax stent was compared with the TAXUS stent, showed in-stent late lumen loss of 0.77 and $0.42 \mathrm{~mm}(P=0.20)$, respectively, and a percentage of stent obstruction by IVUS of $19 \%$ and $6 \%(P=0.08)$, respectively, revealing no significant difference between these two stents in angiography and IVUS quantitative parameters. ${ }^{69,70}$ Minvasys has received the CE Mark for Amazonia Pax stent in 2010.

\section{VESTAsync ${ }^{\text {TM }}$}

In the VESTAsync-eluting stent (MIV Therapeutics, Atlanta, GA), a polymer-free stainless steel platform is incorporated with a nanothin-microporous hydroxyapatite surface coating impregnated with a low-dose lipid-sirolimus mixture. The hydroxyapatite coating dissolves completely after 9-12 months, while the elution of sirolimus is complete within 3 months. The stent has been evaluated in the prospective, nonrandomized, single-center VESTASYNC I FIM clinical trial in 15 patients. Data have confirmed the sustained efficacy of this polymer-free stent showing a lumen late 
loss of $0.36 \pm 0.23 \mathrm{~mm}$ by QCA analysis and an in-stent percentage volume obstruction by IVUS of $4.0 \pm 2.2 \mathrm{~mm}^{3}$ at 9 months follow-up. Long-term clinical follow-up reported no MACE (cardiac/noncardiac death, cerebrovascular accident, nonfatal MI, and stent thrombosis) at 12 months follow-up and only a case of TLR at 36 months follow-up. ${ }^{71}$ In the randomized VESTASYNC II study $(\mathrm{n}=120)$, the VESTAsync sirolimus-eluting stent was compared with a control BMS. The 8-month QCA analysis showed an in-stent late lumen loss of $0.39 \pm 0.20 \mathrm{~mm}$ for VestaSync stent compared with $0.74 \pm 0.52$ on the control BMS $(P=0.03) .{ }^{72}$

\section{Conclusions}

The polymer is one of the main DES elements in charge of hypersensitivity and late stent thrombosis after implantation. Therefore, innovations in this component, as showed by the early results of some devices of this category already used in daily practice, are likely to exert a positive influence on PCI outcomes in the near future.

\section{Innovations in drugs Drugs combination system SymBio ${ }^{\mathrm{TM}}$}

A new solution in developing DES consists of loading a stent with more drugs. This technology has been used in the SymBio stent (Conor Medsystems). This stent includes the Conor reservoirs technology, already used in the Costar stent, which provides the capability to load drug in hundreds of small holes, each acting as a drug-polymer reservoir, and to control the delivery time and rate. In the SymBio stent, in contrast to the Costar stent loaded with paclitaxel, two drugs, specifically paclitaxel and pimecrolimus, are loaded in adjacent reservoirs. Pimecrolimus is an anti-inflammatory agent with immunosuppressant properties used for the topical treatment of atopic dermatitis.

Despite the combination of two drugs in a unique stent, in the randomized, multicenter GENESIS (Randomized, MultiCenter Study of the Pimecrolimus-Eluting and Pimecrolimus/Paclitaxel-Eluting Coronary Stent Systems) trial (NCT00322569), which compared the paclitaxel-eluting Costar stent, the pimecrolimus-eluting Corio ${ }^{\mathrm{TM}}$ stent, and the dual-combination drugs SymBio stent by Conor Medsystem, data failed to demonstrate either SymBio or Corio angiographic noninferiority when compared with paclitaxeleluting stent. The in-stent late loss values at 12 months follow-up were $0.58 \pm 0.58 \mathrm{~mm}$ for the Costar stent, $1.40 \pm 0.67 \mathrm{~mm}$ for the Corio stent, and $0.96 \pm 0.73 \mathrm{~mm}$ for the SymBio stent $(P<0.001){ }^{73}$

\section{New drugs \\ Novolimus \\ Excella $^{\mathrm{TM}}$}

The Excella novolimus-eluting stent (Elixir Medical, Sunnyvale, CA) is a next-generation DES, which consists of a cobalt-chromium platform with a strut thickness of $0.0032^{\prime \prime}$ and eight-crown design for optimal scaffolding, a biocompatible methacrylate polymer with a coating thickness of $<3 \mu \mathrm{m}$ (compared with $7.6 \mu \mathrm{m}$ for everolimus-eluting stents), and a new 'limus' family-related drug called novolimus. This drug is a macrocyclic lactone, metabolite of sirolimus, which demonstrates high potency to inhibit neointimal proliferation. This feature results in a drug dose of $5 \mu \mathrm{g} / \mathrm{mm}$, lower than that found in other stents like zotarolimus- or everolimus-eluting stents $(10 \mu \mathrm{g} / \mathrm{mm})$. Both lower drug dose and polymer load seem to confer to the stent significant safety and efficacy.

The results from the first-in-man EXCELLA I study, which recruited 15 patients, showed an in-stent late loss of $0.31 \pm 0.25 \mathrm{~mm}$ and a neointimal volume of $6.0 \% \pm 4.4 \%$ by IVUS at 8 months follow-up. ${ }^{74}$ Recently, the randomized EXCELLA II (Elixir Medical Clinical Evaluation of the Novolimus-Eluting Coronary Stent System: a Randomized Study With a Single-Arm Registry) study (NCT00792753) demonstrated an angiographic lumen late loss of $0.11 \pm 0.32 \mathrm{~mm}$ and a neointimal volume obstruction of $20.9 \% \pm 11.3 \%{ }^{75}$

\section{Biolimus BioMatrix $^{\mathrm{TM}}$ Flex}

The BioMatrix Flex biolimus-eluting stent (Biosensors) incorporates a stainless steel stent platform with a strut thickness of $112 \mu \mathrm{m}$ and an abluminal PLA biodegradable polymer. The PLA polymer completely degrades into carbon dioxide and water within 6-9 months. In the randomized LEADERS (Trial Limus Eluted from A Durable Versus ERodable Stent Coating) trial (NCT00389220) ( $\mathrm{n}=1707)$, the BioMatrix stent has been compared to the Cypher sirolimus-eluting stent with a noninferiority study design. At 12 months, the BioMatrix stent was noninferior to Cypher stent for MACE (10.6\% and $12.0 \%$, respectively; $P=0.37) .{ }^{76}$ The BioMatrix stent noninferiority to Cypher stent has been ratified at 2 years follow-up with similar outcomes. ${ }^{77}$ Recently, the safety and efficacy of the BioMatrix stent have also been demonstrated in a single-center trial. This study reported an in-stent late loss of $0.24 \pm 0.39 \mathrm{~mm}$ for the BioMatrix group and $0.71 \pm 0.47 \mathrm{~mm}$ for the control group (S-Stent, $P<0.001) .{ }^{78}$ The BioMatrix stent has received the CE Mark. 


\section{Nobori ${ }^{\mathrm{TM}}$}

The Nobori stent (Terumo Corporation, Tokyo, Japan) elutes Biolimus A9 and consists of the stainless steel S-stent and a biodegradable PLA polymer, similar to that of the BioMatrix stent, except for the delivery system and the stent coating process. For the nonrandomized, multicenter Nobori Core study, 107 patients were recruited to demonstrate the similarity between the Nobori stent and Cypher stent. It reported an in-stent late loss of $0.10 \pm 0.26$ and $0.13 \pm 0.44 \mathrm{~mm}$ $(P=0.66)$, respectively, at 9 months angiographic follow-up, thus confirming the predefined hypothesis of similarity between the two stents. ${ }^{79}$ The randomized Nobori 1 trial $(n=243)$ demonstrated the noninferiority of the Nobori stent versus TAXUS Libertè stent for the primary endpoint of angiographic in-stent late loss at 9 months postprocedure (Nobori $0.11 \pm 0.30 \mathrm{~mm}$ and TAXUS Libertè $0.32 \pm 0.50 \mathrm{~mm}$; $P=0.001)$. In addition, in both stents, the rate of MACE was low, and no cases of stent thrombosis occurred at the same follow-up..$^{80}$ The Nobori stent has the potential to reduce thrombotic events, promoting a complete endothelial regeneration. ${ }^{81}$ Further and more extensive evaluations of this stent are awaited in the coming years. In particular, for a multicenter, randomized study (NCT01186120), 500 patients are being recruited to compare the Nobori stent with the PROMUS Element stent for long coronary lesions. A randomized trial (NCT01097434), currently enrolling participants (estimated enrollment, 45 patients), will evaluate the superiority of the Nobori stent versus the Xience V stent with regard to the absolute percentage of uncovered stent strut segments. The prospective, randomized ISAR-TEST 6 trial (NCT01068106) will compare the efficacy and the safety of the Nobori stent with that of the Xience V stent. The Nobori stent has received the CE Mark.

\section{Myolimus}

\section{Myolimus $^{\mathrm{TM}}$ Eluting Coronary system}

Myolimus is a macrocyclic lactone, sirolimus analogous, used in the Myolimus ${ }^{\mathrm{TM}}$ Eluting Coronary system (Elixir Medical) in composition with three proprietary polymer technologies: a durable polymer, a biodegradable polymer developed to biodegrade within 6 months, and a biodegradable polymer which biodegrades within 9 months. The results of the single-arm, multicenter, first-in-man study on the Elixir Myolimus-eluting stent with a durable polymer show an instent late loss of $0.15 \pm 0.11 \mathrm{~mm}$ at angiographic analysis and a neointimal volume of $1.4 \% \pm 1.2 \%$ at IVUS at 6 months follow-up. ${ }^{82}$
Clinical data obtained from a single-arm, multicenter, first-in-man study on the Myolimus-eluting stent with bioabsorbable polymers indicate a late lumen loss of $0.13 \pm 0.27 \mathrm{~mm}$ at angiographic analysis and a neointimal volume of $5.4 \% \pm 8.4 \%$ at IVUS at 12 months of follow-up. ${ }^{83}$

\section{Conclusions}

The combination of new drugs, as the biolimus, with other innovative DES components, as biodegradable polymers, has already provided good results, and it is an established fact in the landscape of interventional cardiology.

\section{Biodegradable stents}

In spite of so many improvements in the development of DES, there are still many concerns regarding the neointimal proliferation and the risk of late stent thrombosis by using this technology. These complications have been attributed to the presence of uncovered metal struts in direct contact with blood and to the possibility of incomplete vessel healing. So far, DES have been modified in their components, namely drug, polymer, and platform, by the several aforementioned solutions with the aim of averting the complications of coronary angioplasty.

In contrast to older devices, biodegradable stents represent a new concept of coronary stent. The need for vessel scaffolding is transitory, so a permanent stent is unnecessary after the vessel has healed. Biodegradable stents completely degrade after implantation and, causing the disappearance of any foreign material exposed to blood if endothelialization is delayed or incomplete, they may hypothetically reduce the risk for late stent thrombosis. Moreover, biodegradable stents may have other potential advantages, such as promoting reconstitution of local vascular compliance, avoiding covering of side-branch, facilitating the use of lesion imaging with multislice computed tomography, angiography, or cardiac magnetic resonance, and allowing further surgical or percutaneous treatments to the same lesion. ${ }^{84,85}$ Biodegradable stents were first implanted in 1980s with good results, but none has received either the CE Mark or United States Food and Drug Administration approval. Further ameliorations and large-scale randomized trials with long-term follow-up are necessary to enhance and evaluate the safety and efficacy of this technology.

\section{Poly-L-lactide stents}

\section{Bioresorbable Vascular Scaffold ${ }^{\mathrm{TM}}$}

The Bioresorbable everolimus-eluting Vascular Scaffold (BVS; Abbott Vascular) is made up of a backbone of PLLA coated with a thin layer of poly-D,L-lactide (PDLLA) 
and elutes everolimus. PLLA is a fully biodegradable semicrystalline polymer, which forms a conglomeration of crystalline and amorphous phases when it solidifies. The structure and the state of this polymer change in relation to temperature and deformation history. PDLLA is a biodegradable polymer coating PLLA, which forms, similar to the PLLA, an amorphous phase when it solidifies at room and physiological temperatures. The PDLLA allows controlled release of the drug such that $\sim 80 \%$ of everolimus is eluted within 28 days. The absorption process of PLLA and PDLLA occurs via hydrolysis, producing lactic acid, and subsequently degrades via the Krebs cycle, and small particles $<2 \mu \mathrm{m}$ in diameter are phagocytosed by macrophages. With regard to preclinical trials, it seems that complete absorption of the stent could occur within 2-3 years after implantation (Figure 4).

Two versions of the stent have been developed. The design of the BVS stent Revision 1.0 consists of circumferential out-of-phase zigzag hoops of PLLA with a strut thickness of $150 \mu \mathrm{m}$, linked either directly or by straight bridges, with two radiopaque markers at each end which enable a good visualization on angiography. It has been evaluated in 30 patients in the cohort A of the prospective, open-labeled, first-in-man ABSORB (Bioabsorbable Vascular Solutions First-in-Man Clinical Investigation: a Clinical Evaluation of the Bioabsorbable Vascular Solutions Everolimus-Eluting Coronary Stent System in the Treatment of Patients With Single de Novo Native Coronary Artery Lesions) study (NCT00300131). ${ }^{86}$ The in-stent late loss reported at 2 years angiographic follow-up did not significantly differ from that found at 6 months follow-up $(0.48 \pm 0.28 \mathrm{~mm}$ vs $0.43 \pm 0.37 \mathrm{~mm}$; $P=0.233$ ). The multi-imaging approach (IVUS-virtual histology and OCT) at the same follow-up showed that the stent was incorporated into the vessel wall and that several

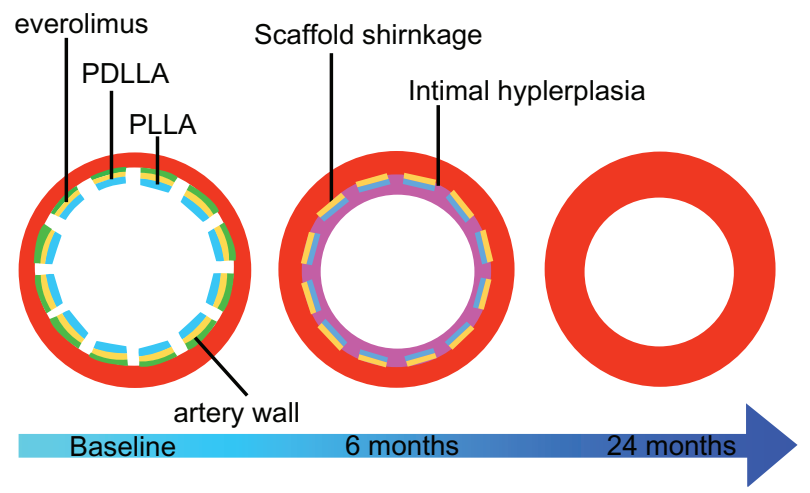

Figure 4 Bioabsorption process of the BVS stent and relative degradation times. Abbreviations: PDLLA, poly-D,L-lactic acid; PLLA, poly-L-lactic acid; BVS, bioresorbable vascular scaffold. implanted stents were no longer discernible by OCT. ${ }^{87}$ The rate of MACE at 6 months follow-up was 3.3\%, and no new MACE events occurred between 6 months and 3 years. No stent thrombosis or TLR occurred up to 3 years follow-up. A significant restoration of vasomotion was reported at the same follow-up, but the study showed some limitations. In particular, the duration of radial support may be insufficient to resist the coronary remodeling after PCI, and the scaffold shrinkage could cause quite high in-stent late loss value reported at 6 months follow-up. ${ }^{88}$

The BVS Revision 1.1 consists of the same polymer, but different process refinements allow the stent to increase its radial force, provide radial support for a longer time, and, consequently, avoid the slightly higher, but nonsignificant, recoil shown by QCA. ${ }^{89-91}$ This stent version has a different strut distribution, reducing the maximum circular unsupported cross-sectional area, in contrast to BVS Revision 1.0.92 It is currently under evaluation in the Cohort B of the nonrandomized ABSORB trial (NCT00856856) in 80 patients. Data reported an in-scaffold late loss of $0.19 \mathrm{~mm}$ at 6 months angiographic follow-up and a MACE rate of 4.4\% (TVF $4.4 \%$ ) at 9 months clinical follow-up (one non-Q wave MI and one ischemia driven-TLR); no scaffold thrombosis occurred over the follow-up. ${ }^{93}$

\section{REVA $^{\text {TM }}$}

The scaffolding of the REVA bioabsorbable stent (REVA Medical, San Diego, CA) consists of a biodegradable tyrosine polycarbonate polymer, which metabolizes to amino acids, ethanol, and carbon dioxide. The rate of re-absorption depends on molecular weight and can be modified for different utilizations, for example, specific use in vulnerable plaques or diabetic lesions. This polymer is also radiopaque because of binding iodine molecules directly into the polymer backbone. The expansion mechanism of the stent is based on the 'slide and lock design'. This technology enables the stent to expand without significant deformation, providing high-radial strength compared to stainless stent with negligible recoil $(<1 \%) .{ }^{94}$ The first-generation stent, which did not elute any drug, has been assessed in the prospective, multicenter, single-arm, safety, first-in-man RESORB (REVA Endovascular Study of a Bioresorbable Coronary Stent) study (27 patients enrolled), which showed a higher than anticipated rate of TLR at 4-6 months follow-up, most likely caused by reduction in stent diameter, even though without evidence of shrinkage or negative vessel remodeling. ${ }^{95,96}$ The next-generation stent, called the ReZolve ${ }^{\mathrm{TM}}$ stent, 
uses a 'slide and lock' mechanism, but it has been optimized using a coating of sirolimus, a more robust material, and a spiral design to enhance dimensional stability and to maintain mechanical integrity under high loading both initially and over time. This stent is undergoing clinical evaluation. ${ }^{97}$

\section{BTITM}

A bioabsorbable polymer of salicylic acid, the active ingredient of aspirin with anti-inflammatory and antiplatelet properties, constitutes the basis for the BTI stent (Bioabsorbable Therapeutics Inc, Menlo Park, CA). The stent has two layers composed of salicylic-acid derivates: the core provides mechanical scaffolding, while the surface layer contains sirolimus that is eluted during the biodegradation process together with a dose of salicylic acid of $\sim 10 \mu \mathrm{g} .{ }^{98}$ The blend of sirolimus and salicylic acid ensures both antiproliferative and anti-inflammatory actions. The complete absorption of the stent is expected within 6-12 months. Following successful preclinical trials on porcine coronary arteries, the multicenter first-in-man WHISPER trial demonstrated acceptable safety and the absence of acute or chronic recoil, but on the other hand, data reported an insufficient neointimal suppression presumably due to the low dose and very rapid elution of sirolimus. As a result, the firstgeneration stent has been modified by increasing the drug dose and slowing down the elution time. Today, this secondgeneration stent is under testing in a preclinical trial on porcine coronaries. ${ }^{99,100}$

\section{IGAKI-TAMAI TM}

The bioabsorbable IGAKI-TAMAI stent (Kyoto Medical Planning Co Ltd, Kyoto, Japan) is made up of a monofilament of PLLA polymer (thickness: 0.17 ) with a zigzag design. It has two radiopaque gold markers at each end to facilitate visualization on angiography. This PLLA stent is both thermal self-expanding and balloon expandable; it gets its original size in $0.2 \mathrm{sec}$ when heated to $70^{\circ} \mathrm{C}$. The stent expansion in the implant site by balloon occurs within $30 \mathrm{sec}$ and is performed by balloon inflation of a heated dye at $80^{\circ} \mathrm{C}$. After the inflation process, the self-dilatation continues progressively until the definitive equilibrium size. The IGAKI-TAMAI stent was the first-biodegradable stent implanted in a human. The first version of the stent lacked an antiproliferative drug. In the first-in-man study, it was evaluated on 15 patients treated with 25 stents in 19 lesions. Data reported at 6 months indicate a late loss of $0.48 \pm 0.32$ and no ST or MACE at clinical follow-up, but the rates of angiographic restenosis and of TLR per lesion were both $10.5 \%$. IVUS revealed an expansion of the stent over the follow-up and the presence of stent strut at 6 months; in addition, the mean stent crosssectional area was similar at 3 and 6 months $(8.18$ and $\left.8.13 \mathrm{~mm}^{2} ; P=0.30\right){ }^{101}$

In another study, in which 50 elective patients with 63 lesions treated with 84 IGAKI-TAMAI stents were enrolled, a 10-year follow-up (the longest available follow-up of a biodegradable coronary stent) reported rates of cardiac and noncardiac death-free survival of $97.8 \%$ and $87.0 \%$, respectively, a rate of MACE-free survival of $48.4 \%$, and a rate of TLR of $23.8 \% .^{102,103}$ Data showed a low complication rate, but at present, due to concerns about the use of heat to induce self-expansion, no further human coronary implants have been carried out, and today, the stent is only available in Europe for peripheral use. A version of the stent with a coating of paclitaxel has been deployed in porcine coronary arteries; the drug coating was shown to effectively inhibit proliferation and coronary stenosis after vascular intervention in a long-term follow-up. ${ }^{104}$

\section{Bioabsorbable magnesium stent}

One of the problems with the bioabsorbable stent is the abovementioned lower radial strength when compared to stainless steel traditional devices. Biodegradable metallic stents have been developed with the aim of exceeding these limitations; in particular, they provide a combination of the advantages of a polymeric biodegradable stent, such as the complete degradation of the implants and a fast recovery of vasomotion, with the benefits of stainless steel stents, including an effective radial force.

The absorbable-metal stent (AMS; Biotronik, Berlin, Germany) is a balloon-expandable stent, laser cut from a tube of bioabsorbable alloy which is composed mainly of magnesium $(>90 \%)$. This technology for tube production provides a reduced wall thickness. The expected degradation time is $<56$ days. ${ }^{105}$ Three generations of stent have been designed. The first-generation stent (AMS-1), which lacked a drug coating, was evaluated in 63 patients in the prospective, nonrandomized, multicenter PROGRESS-AMS trial, showing no deaths, nonfatal MIs, or stent thromboses at 4 and 12 months follow-up. On the other hand, the rate of TLR was $39.7 \%$ and $45 \%$ at 4 and 12 months follow-up, respectively, and the in-stent late loss was $1.08 \pm 0.49 \mathrm{~mm}$ at 4 months angiographic follow-up. ${ }^{106}$

A second-generation stent, called AMS-2, was developed to improve the results of the AMS-1. It is characterized by a slower degradation, a thinner strut thickness, and a modern design. In preclinical studies, the AMS-2 demonstrated 
encouraging results with regard to neointimal proliferation and to prolonged stent integrity. After the AMS-2, a further version of the stent, called AMS-3, has been developed. This version of the stent, which is the first drug-eluting absorbable magnesium stent, has already been reported in animal trials and showed significant improvement in minimum lumen diameter at 14 and 28 days compared to AMS-1 and late loss indices comparable to conventional DES. ${ }^{107}$ Currently, the nonrandomized first-in-man trial BIOSOLVE-I (BIOTRONIKS-Safety and Clinical Performance Of the First Drug-Eluting Generation Absorbable Metal Stent In Patients With de Novo Lesions in NatiVE Coronary Arteries. NCT01168830), which will assess the safety of the AMS-3, is recruiting participants.

\section{Conclusions}

Recent approaches in development of next-generation DES have been reported in this review. In past years, a lot of effort has been devoted to improving the safety and efficacy of new coronary stents. Some of the above are already available for daily practice, while others need further studies to validate their use on humans. Larger trials and longer follow-up are necessary to assess the effectiveness of these novel devices, but, given that DES will continue to have a prominent part in PCI in the near future, the aims so far reached suggest the achievement of important results.

\section{Acknowledgment}

Corrado Tamburino has received speaker's honoraria from Abbott Vascular, Medtronic, and Celonova Bioscience.

\section{Disclosure}

Davide Capodanno and Fabio Dipasqua report no conflicts of interest.

\section{References}

1. Hoffmann R, Mintz GS, Dussaillant GR, et al. Patterns and mechanisms of in-stent restenosis. A serial intravascular ultrasound study. Circulation. 1996;94(6):1247-1254.

2. Sousa JE, Costa MA, Abizaid AC, et al. Sustained suppression of neointimal proliferation by sirolimus-eluting stents: one-year angiographic and intravascular ultrasound follow-up. Circulation. 2001; 104(17):2007-2011.

3. Htay T, Liu MW. Drug-eluting stent: a review and update. Vasc Health Risk Manag. 2005;1(4):263-276.

4. Morice MC, Colombo A, Meier B, et al; REALITY Trial Investigators. Sirolimus- vs paclitaxel-eluting stents in de novo coronary artery lesions: the REALITY trial: a randomized controlled trial. JAMA. 2006;295(8): 895-904.

5. Millauer N, Jüni P, Hofmann A, et al. Sirolimus versus paclitaxel coronary stents in clinical practice. Catheter Cardiovasc Interv. 2011; 77(1):5-12.
6. Abizaid A. Sirolimus-eluting coronary stents: a review. Vasc Health Risk Manag. 2007;3(2):191-201.

7. Uyan C, Arinc H, Gunduz H, Akdemir R. Immediate and six months clinical and angiographic results of intracoronary paclitaxel-coated stent implantation - the Meo:DrugStar-1 study. Vasc Health Risk Manag. 2008;4(1):173-176.

8. Kirchner RM, Abbott JD. Update on the everolimus-eluting coronary stent system: results and implications from the SPIRIT clinical trial program. Vasc Health Risk Manag. 2009;5:1089-1097.

9. Sheiban I, Villata G, Bollati M, Sillano D, Lotrionte M, Biondi-Zoccai G. Next-generation drug-eluting stents in coronary artery disease: focus on everolimus-eluting stent (Xience V). Vasc Health Risk Manag. 2008; $4(1): 31-38$.

10. Virmani R, Guagliumi G, Farb A, et al. Localized hypersensitivity and late coronary thrombosis secondary to a sirolimus-eluting stent: should we be cautious? Circulation. 2004;109(6):701-705.

11. Camenzind E, Steg PG, Wijns W. Stent thrombosis late after implantation of first-generation drug-eluting stents: a cause for concern. Circulation. 2007;115(11):1440-1455; discussion 1455.

12. Togni M, Windecker S, Cocchia R, et al. Sirolimus-eluting stents associated with paradoxic coronary vasoconstriction. J Am Coll Cardiol. 2005;46(2):231-236.

13. Joner M, Finn AV, Farb A, et al. Pathology of drug-eluting stents in humans: delayed healing and late thrombotic risk. J Am Coll Cardiol. 2006;48(1):193-202.

14. Kereiakes DJ, Cannon LA, Feldman RL, et al. Clinical and angiographic outcomes after treatment of de novo coronary stenoses with a novel platinum chromium thin-strut stent: primary results of the PERSEUS (Prospective Evaluation in a Randomized Trial of the Safety and Efficacy of the Use of the TAXUS Element Paclitaxel-Eluting Coronary Stent System) trial. J Am Coll Cardiol. 2010;56(4):264-271.

15. Chieffo A, Aranzulla TC, Colombo A. Drug eluting stents: focus on Cypher sirolimus-eluting coronary stents in the treatment of patients with bifurcation lesions. Vasc Health Risk Manag. 2007;3(4): 441-451.

16. Lefèvre T, Ormiston J, Guagliumi G, et al. The Frontier stent registry: safety and feasibility of a novel dedicated stent for the treatment of bifurcation coronary artery lesions. J Am Coll Cardiol. 2005;46(4): 592-598.

17. Ikeno F, Kim YH, Luna J, et al. Acute and long-term outcomes of the novel side access (SLK-View) stent for bifurcation coronary lesions: a multicenter non-randomized feasibility study. Catheter Cardiovasc Interv. 2006;67(2):198-206.

18. Ormiston J, Webster M, El-Jack S, McNab D, Plaumann SS. The AST petal dedicated bifurcation stent: first-in-human experience. Catheter Cardiovasc Interv. 2007;70(3):335-340.

19. Doi H, Maehara A, Mintz GS, Dani L, Leon MB, Grube E. Serial intravascular ultrasound analysis of bifurcation lesions treated using the novel self-expanding sideguard side branch stent. Am J Cardiol. 2009;104(9):1216-1221.

20. Grube E. Bifurcation and left main dedicated stents. Proceedings of TCT; 2009 Sep 21-25; San Francisco.

21. Albiero R. Invatec twin-rail stent: design features and clinical updates. Proceedings of TCT; 2008 Oct 12-17; Washington.

22. Van Geuns RJ. The Minvasys Nile paclitaxel-eluting sidebranch access stent: results from the BiPAX study. Proceedings of TCT; 2009 Sep 21-25; San Francisco.

23. Onuma Y, Müller R, Ramcharitar S, et al. Tryton I, First-In-Man (FIM) study: six month clinical and angiographic outcome, analysis with new quantitative coronary angiography dedicated for bifurcation lesions. EuroIntervention. 2008;3(5):546-552.

24. Ischinger TA. New devices for complex vascular interventions. The Y-Med catheter technology. Proceedings of Euro PCR; 2006 May 16-19; Paris, France.

25. Hermiller JB. The TriReme Medical Antares sidebranch access stent: design specifications and clinical trial results. Proceedings of TCT; 2009 Sep 21-25; San Francisco. 
26. Sheiban I, Omedé P, Biondi-Zoccai G, Moretti C, Sciuto F, Trevi GP. Update on dedicated bifurcation stents. J Interv Cardiol. 2009;22(2): $150-155$.

27. Grube E, Buellesfeld L, Neumann FJ, et al. Six-month clinical and angiographic results of a dedicated drug-eluting stent for the treatment of coronary bifurcation narrowings. Am J Cardiol. 2007;99(12): $1691-1697$.

28. Verheye S, Agostoni P, Dubois CL, et al. 9-month clinical, angiographic, and intravascular ultrasound results of a prospective evaluation of the Axxess self-expanding biolimus A9-eluting stent in coronary bifurcation lesions: the DIVERGE (Drug-Eluting Stent Intervention for Treating Side Branches Effectively) study. J Am Coll Cardiol. 2009;53(12): 1031-1039.

29. Ormiston JA, Lefèvre T, Grube E, Allocco DJ, Dawkins KD. First human use of the TAXUS Petal paclitaxel-eluting bifurcation stent. EuroIntervention. 2010;6(1):46-53.

30. Van Geuns RJ. The Minvasys Nile paclitaxel-eluting sidebranch access stent: design specifications and clinical trial results. Proceedings of TCT; 2009 Sep 21-25; San Francisco.

31. Costa RA. BIPAX bifurcation study: first results. Proceedings of Euro PCR; 2010 May 25-28; Paris, France.

32. Verheye S, Grube E, Ramcharitar S, et al. First-in-man (FIM) study of the Stentys bifurcation stent -30 days results. EuroIntervention. 2009;4(5):566-571.

33. Verheye S. Latest results of the STENTYS clinical programme. Proceedings of Euro PCR; 2010 May 25-28; Paris, France.

34. Van Geuns RJ. APPOSITION II study results. Proceedings of TCT; 2010 Sep 21-25; Washington.

35. Rathore S. Small coronary vessel angioplasty: outcomes and technical considerations. Vasc Health Risk Manag. 2010;6:915-922.

36. Tanimoto S, Daemen J, Serruys PW. Update on stents: recent studies on the TAXUS stent system in small vessels. Vasc Health Risk Manag. 2007;3(4):481-490.

37. Abizaid AC, de Ribamar Costa Junior J, Whitbourn RJ, Chang JC. The CardioMind coronary stent delivery system: stent delivery on a 0.014" guidewire platform. EuroIntervention. 2007;3(1):154-157.

38. Whitbourn RJ. The CARDIOMIND stent-on-a-wire self-expanding micro-stent: results from CARE I (two year follow-up) and introduction to CARE II (sirolimus-eluting micro-stent). Proceedings of TCT; 2008 Oct 12-17; Washington.

39. Botelho R. The Cardiomind Sparrow DES program (CARE II): a bioabsorbable polymer sirolimus-eluting 'micro-stent'. Proceedings of TCT; 2009 Sep 21-25; San Francisco.

40. Abizaid AC, et al. CARE II 8 month follow-up results with the CardioMind 0.014" Sparrow sirolimus-eluting nitinol stent system. J Am Coll Cardiol. 2010;56:B53.

41. Meredith IT, Worthley S, Whitbourn R, et al; RESOLUTE Investigators. Clinical and angiographic results with the next-generation resolute stent system: a prospective, multicenter, first-in-human trial. JACC Cardiovasc Interv. 2009;2(10):977-985.

42. Udipi K, Melder RJ, Chen M, et al. The next generation Endeavor Resolute Stent: role of the BioLinx Polymer System. EuroIntervention. 2007;3(1):137-139.

43. Meredith IT, Worthley SG, Whitbourn R, et al. Long-term clinical outcomes with the next-generation Resolute Stent System: a report of the two-year follow-up from the RESOLUTE clinical trial. EuroIntervention. 2010;5(6):692-697.

44. Silber S. RESOLUTE: new insights from resolute all-comers. Proceedings of TCT; 2010 Sep 21-25; Washington.

45. Dani S, Kukreja N, Parikh P, et al. Biodegradable-polymer-based, sirolimus-eluting Supralimus stent: 6-month angiographic and 30-month clinical follow-up results from the series I prospective study. EuroIntervention. 2008;4(1):59-63.

46. Costa J. Supralimus bioabsorbable-polymer sirolimus-eluting stent technology in patients with acute coronary syndrome undergoing percutaneous coronary intervention: initial results of the prospective, international, multicenter, E-SERIES registry. Proceedings of TCT; 2009 Sep 21-25; San Francisco.
47. Han Y, Jing Q, Xu B, et al; CREATE (Multi-Center Registry of Excel Biodegradable Polymer Drug-Eluting Stents) Investigators. Safety and efficacy of biodegradable polymer-coated sirolimus-eluting stents in 'real-world' practice: 18-month clinical and 9-month angiographic outcomes. JACC Cardiovasc Interv. 2009;2(4):303-309.

48. Falotico R, Parker T, Grishaber R, Price S, Cohen SA, Rogers C. $\mathrm{NEVO}^{\mathrm{TM}}$ : a new generation of sirolimus-eluting coronary stent. EuroIntervention. 2009;5 Suppl F:F88-F93.

49. Spaulding C, Ormiston JA, Abizaid A; on behalf of the NEVO RES-I Investigators. 6 Months results of the NEVO RES-ELUTION I (RES-I) trial. A randomized, multi-center, single-blind comparison of the $\mathrm{NEVO}^{\mathrm{TM}}$ sirolimus-eluting coronary stent versus the TAXUS ${ }^{\mathrm{TM}}$ Liberté paclitaxel-eluting coronary stent system in de novo native coronary artery lesions. Proceedings of Euro PCR; 2009 May 19-22; Barcelona, Spain.

50. Mauri L; on behalf of NEVO RES-I Investigators. NEVO RES-elution trial - 12-month results and pivotal trial overview. Proceedings of TCT; 2010 Sep 21-25; Washington.

51. Vranckx P, Serruys PW, Gambhir S, et al. Biodegradable-polymerbased, paclitaxel-eluting infinnium stent: 9-month clinical and angiographic follow-up results from the SIMPLE II prospective multi-centre registry study. EuroIntervention. 2006;2(3):310-317.

52. Lemos PA, Moulin B, Perin MA, et al; PAINT Trial Investigators. Randomized evaluation of two drug-eluting stents with identical metallic platform and biodegradable polymer but different agents (paclitaxel or sirolimus) compared against bare stents: 1-year results of the PAINT trial. Catheter Cardiovasc Interv. 2009;74(5):665-673.

53. Guagliumi G, Valsecchi O, Aprile A, et al. JACTAX paclitaxel-eluting stent program. Ultra-thin abluminal PLA polymer. Focus on the randomized OCTDESI strut coverage evaluation. Proceedings of TCT; 2009 Sep 21-25; San Francisco.

54. Guagliumi G, Sirbu V, Musumeci G, et al. Strut coverage and vessel wall response to a new-generation paclitaxel-eluting stent with an ultrathin biodegradable abluminal polymer: Optical Coherence Tomography Drug-Eluting Stent Investigation (OCTDESI). Circ Cardiovasc Interv. 2010;3(4):367-375.

55. Turco MA, Ormiston JA, Popma JJ, et al. Polymer-based, paclitaxeleluting TAXUS Liberté stent in de novo lesions: the pivotal TAXUS ATLAS trial. J Am Coll Cardiol. 2007;49(16):1676-1683.

56. Grube E, Schofer J, Hauptmann KE, et al. A novel paclitaxel-eluting stent with an ultrathin abluminal biodegradable polymer 9-month outcomes with the JACTAX HD stent. JACC Cardiovasc Interv. 2010; 3(4):431-438

57. Serruys PW, Sianos G, Abizaid A, et al. The effect of variable dose and release kinetics on neointimal hyperplasia using a novel paclitaxeleluting stent platform: the Paclitaxel In-Stent Controlled Elution Study (PISCES). J Am Coll Cardiol. 2005;46(2):253-260.

58. Kaul U, Gupta RK, Mathur A, et al. Cobalt chromium stent with antiproliferative for restenosis trial in India (COSTAR I). Indian Heart $J$. 2007;59(2):165-172.

59. Dawkins KD, Verheye S, Schühlen H, et al. The European cobalt STent with Antiproliferative for Restenosis trial (EuroSTAR): 12 month results. EuroIntervention. 2007;3(1):82-88.

60. Krucoff MW, Kereiakes DJ, Petersen JL, et al; COSTAR II Investigators Group. A novel bioresorbable polymer paclitaxel-eluting stent for the treatment of single and multivessel coronary disease: primary results of the COSTAR (Cobalt Chromium Stent With Antiproliferative for Restenosis) II study. J Am Coll Cardiol. 2008;51(16): $1543-1552$.

61. Wessely R, Hausleiter J, Michaelis C, et al. Inhibition of neointima formation by a novel drug-eluting stent system that allows for doseadjustable, multiple, and on-site stent coating. Arterioscler Thromb Vasc Biol. 2005;25(4):748-753.

62. Hausleiter J, Kastrati A, Wessely R, et al; Investigators of the Individualizable Drug-Eluting Stent System to Abrogate Restenosis Project. Prevention of restenosis by a novel drug-eluting stent system with a dose-adjustable, polymer-free, on-site stent coating. Eur Heart $J$. 2005;26(15):1475-1481. 
63. Mehilli J, Kastrati A, Wessely R, et al; Intracoronary Stenting and Angiographic Restenosis-Test Equivalence Between 2 Drug-Eluting Stents (ISAR-TEST) Trial Investigators. Randomized trial of a nonpolymer-based rapamycin-eluting stent versus a polymer-based paclitaxel-eluting stent for the reduction of late lumen loss. Circulation. 2006;113(2):273-279.

64. Fitzgerald P. Commentary: ISAR test 3. Proceedings of TCT; 2008 Oct 12-17; Washington.

65. Ruef J, Storger H, Schwarz F, Haase J. Comparison of a polymer-free rapamycin-eluting stent (YUKON) with a polymer-based paclitaxeleluting stent (TAXUS) in real-world coronary artery lesions. Catheter Cardiovasc Interv. 2008;71(3):333-339.

66. Byrne RA, Iijima R, Mehilli J, et al. Durability of antirestenotic efficacy in drug-eluting stents with and without permanent polymer. JACC Cardiovasc Interv. 2009;2(4):291-299.

67. Grube E. BIOFREEDOM: a prospective randomized trial of polymerfree biolimus a9-eluting stents and paclitaxel-eluting stents in patients with coronary artery disease. Proceedings of TCT; 2009 Sep 21-25; San Francisco.

68. Tada N, Virmani R, Grant G, et al. Polymer-free biolimus a9-coated stent demonstrates more sustained intimal inhibition, improved healing, and reduced inflammation compared with a polymer-coated sirolimuseluting cypher stent in a porcine model. Circ Cardiovasc Interv. 2010; 3(2):174-183.

69. Fajadet J. The Minvasys Amazonia PAX and Nile PAX polymer free paclitaxel eluting stent program. Proceedings of TCT; 2009 Sep 21-25; San Francisco.

70. Abizaid A. PAX A trial: 4-months follow-up results. Proceedings of Euro PCR; 2010 May 25-28; Paris, France.

71. Costa JR Jr, Abizaid A, Costa R, et al. 1-year results of the hydroxyapatite polymer-free sirolimus-eluting stent for the treatment of single de novo coronary lesions: the VESTASYNC I trial. JACC Cardiovasc Interv. 2009;2(5):422-427.

72. Abizaid A. VESTAsync I update, and First Report of the VESTAsync II randomized trial with a hydroxyapatite polymer-free sirolimus-eluting stent. Proceedings of TCT; 2009 Sep 21-25; San Francisco.

73. Verheye S, Agostoni P, Dawkins KD, et al. The GENESIS (Randomized, Multicenter Study of the Pimecrolimus-Eluting and Pimecrolimus/ Paclitaxel-Eluting Coronary Stent System in Patients with De Novo Lesions of the Native Coronary Arteries) trial. JACC Cardiovasc Interv. 2009;2(3):205-214.

74. Costa JR Jr, Abizaid A, Feres F, et al. EXCELLA First-in-Man (FIM) study: safety and efficacy of novolimus-eluting stent in de novo coronary lesions. EuroIntervention. 2008;4(1):53-58.

75. Serruys PW, Garg S, Abizaid A, et al. A randomised comparison of novolimus-eluting and zotarolimus-eluting coronary stents: 9-month follow-up results of the EXCELLA II study. EuroIntervention. 2010; 6(2):195-205.

76. Garg S, Sarno G, Serruys PW, et al. The twelve-month outcomes of a biolimus eluting stent with a biodegradable polymer compared with a sirolimus eluting stent with a durable polymer. EuroIntervention. 2010; 6(2):233-239.

77. Klauss V. LEADERS: two-year follow-up from a prospective randomized trial of biolimus A9-eluting stents with a bioabsorbable polymer vs. sirolimus-eluting stents with a durable polymer. Proceedings of TCT; 2009 Sep 21-25; San Francisco.

78. Esteves V, Abizaid A, Centemero MP, et al. Five-year clinical results of the biolimus A9 eluting stent with biodegradable polymer. Proceedings of Euro PCR; 2010 May 25-28; Paris, France.

79. Ostojic M, Sagic D, Beleslin B, et al. First clinical comparison of Nobori-Biolimus A9 eluting stents with Cypher-Sirolimus eluting stents: Nobori Core nine months angiographic and one year clinical outcomes. EuroIntervention. 2008;3(5):574-579.

80. Chevalier B, Silber S, Park SJ, et al; NOBORI 1 Clinical Investigators. Randomized comparison of the Nobori Biolimus A9-eluting coronary stent with the Taxus Liberté paclitaxel-eluting coronary stent in patients with stenosis in native coronary arteries: the NOBORI 1 trial - Phase 2. Circ Cardiovasc Interv. 2009;2(3):188-195.
81. Hamilos MI, Ostojic M, Beleslin B, et al; NOBORI CORE Investigators. Differential effects of drug-eluting stents on local endotheliumdependent coronary vasomotion. J Am Coll Cardiol. 2008;51(22): 2123-2129.

82. Rutsch W, Witzenbichler B, Schuhlen H. Multicentre first-in-man study with the lowest known limus dose on the Elixir medical myolimus ${ }^{\mathrm{TM}}$ eluting coronary stent system with a durable polymer: 12 -month clinical and six month angiographic and IVUS follow-up. Proceedings of Euro PCR; 2009 May 19-22; Barcelona, Spain.

83. Schoefer J, Dudek D, Witzenbichler B, et al. Multicenter, first-in-man study on the Elixir Myolimus-eluting coronary stent system with bioabsorbable polymer: 12-month clinical and angiographic/IVUS results. Proceedings of Euro PCR; 2010 May 25-28; Paris, France.

84. Wykrzykowska JJ, Onuma Y, Serruys PW. Advances in stent drug delivery: the future is in bioabsorbable stents. Expert Opin Drug Deliv. 2009;6(2):113-126.

85. Ormiston JA, Serruys PW. Bioabsorbable coronary stents. Circ Cardiovasc Interv. 2009;2(3):255-260.

86. Ormiston JA, Serruys PW, Regar E, et al. A bioabsorbable everolimuseluting coronary stent system for patients with single de-novo coronary artery lesions (ABSORB): a prospective open-label trial. Lancet. 2008; 371(9616):899-907.

87. Serruys PW, Ormiston JA, Onuma Y, et al. A bioabsorbable everolimuseluting coronary stent system (ABSORB): 2-year outcomes and results from multiple imaging methods. Lancet. 2009;373(9667):897-910.

88. Ormiston JA. BVS cohort A: four year results and lessons learned. Proceedings of TCT; 2010 Sep 21-25; Washington.

89. Tanimoto S, Serruys PW, Thuesen L, et al. Comparison of in vivo acute stent recoil between the bioabsorbable everolimus-eluting coronary stent and the everolimus-eluting cobalt chromium coronary stent: insights from the ABSORB and SPIRIT trials. Catheter Cardiovasc Interv. 2007;70(4):515-523.

90. García-García HM, Gonzalo N, Pawar R, et al. Assessment of the absorption process following bioabsorbable everolimus-eluting stent implantation: temporal changes in strain values and tissue composition using intravascular ultrasound radiofrequency data analysis. A substudy of the ABSORB clinical trial. EuroIntervention. 2009;4(4): 443-448.

91. Sarno G, Onuma Y, Garcia Garcia HM, et al. IVUS radiofrequency analysis in the evaluation of the polymeric struts of the bioabsorbable everolimus-eluting device during the bioabsorption process. Catheter Cardiovasc Interv. 2010;75(6):914-918.

92. Okamura T, Garg S, Gutiérrez-Chico JL, et al. In vivo evaluation of stent strut distribution patterns in the bioabsorbable everolimus-eluting device: an OCT ad hoc analysis of the revision 1.0 and revision 1.1 stent design in the ABSORB clinical trial. EuroIntervention. 2010;5(8): 932-938.

93. Serruys PW. BVS cohort B: device design, 6-month update, and first report of the 12-month results. Proceedings of TCT; 2010 Sep 21-25; Washington.

94. Kaluza GL. Current status of polymeric biodegradable drug eluting stents II: REVA Medical, Inc. Proceedings of TCT; 2006 Oct 22-27; Washington.

95. Grube E. The REVA tyrosine-derived polycarbonate bioabsorbable stent: final results from the RESORB first-in-man clinical trial and next generation designs. Proceedings of TCT; 2008 Oct 12-17; Washington.

96. Pollman MJ. Engineering a bioresorbable stent: REVA programme update. EuroIntervention. 2009;5 Suppl F:F54-F57.

97. Abizaid A. The REVA tyrosine-derived polycarbonate bioabsorbable stent: lessons learned and future directions. Proceedings of TCT; 2009 Sep 21-25; San Francisco.

98. Jabara R, Pendyala L, Geva S, Chen J, Chronos N, Robinson K. Novel fully bioabsorbale salicylate-based sirolimuseluting stent. EuroIntervention. 2009;5 Suppl F:F58-F64.

99. Abizaid A. The BTI salycilate-based polyanhydride ester absorbable sirolimus-eluting stent: update from the Whisper study. Proceedings of TCT; 2008 Oct 12-17; Washington. 
100. Jabara R. Poly-anhydride based on salicylic acid and adipic acid anhydride. Proceedings of Euro PCR; 2009 May 19-22; Barcelona, Spain.

101. Tamai H, Igaki K, Kyo E, et al. Initial and 6-month results of biodegradable poly-L-lactic acid coronary stents in humans. Circulation. 2000;102(4):399-404.

102. Nishio $\mathrm{S}$, et al. Long-term $(>10$ years) clinical outcomes of firstin-man biodegradable poly-L-lactic acid coronary stents. Proceedings of Euro PCR; 2010 May 25-28; Paris, France.

103. Onuma Y, Garg S, Okamura T, et al. Ten-year follow-up of the IGAKITAMAI stent. A posthumous tribute to the scientific work of Dr. Hideo Tamai. EuroIntervention. 2009;5 Suppl F:F109-F111.

104. Vogt F, Stein A, Rettemeier G, et al. Long-term assessment of a novel biodegradable paclitaxel-eluting coronary polylactide stent. Eur Heart J. 2004;25(15):1330-1340.
105. Heublein B, Rohde R, Kaese V, Niemeyer M, Hartung W, Haverich A. Biocorrosion of magnesium alloys: a new principle in cardiovascular implant technology? Heart. 2003;89(6):651-656.

106. Erbel R, Di Mario C, Bartunek J, et al; PROGRESS-AMS (Clinical Performance and Angiographic Results of Coronary Stenting with Absorbable Metal Stents) Investigators. Temporary scaffolding of coronary arteries with bioabsorbable magnesium stents: a prospective, non-randomised multicentre trial. Lancet. 2007;369(9576): 1869-1875.

107. Waksman R. Current state of the absorbable metallic (magnesium) stent. EuroIntervention. 2009;5 Suppl F:F94-F98.

\section{Publish your work in this journal}

Vascular Health and Risk Management is an international, peer-reviewed journal of therapeutics and risk management, focusing on concise rapid reporting of clinical studies on the processes involved in the maintenance of vascular health; the monitoring, prevention and treatment of vascular disease and its sequelae; and the involvement of metabolic disorders, particularly diabetes. This journal is indexed on PubMed Central and MedLine. The manuscript management system is completely online and includes a very quick and fair peer-review system, which is all easy to use. Visit http://www.dovepress.com/ testimonials.php to read real quotes from published authors.

Submit your manuscript here: http://www.dovepress.com/vascular-health-and-risk-management-journal 